\title{
Does the level of expressed emotion (LEE) questionnaire have the same factor structure for adolescents as it has for adults?
}

Abstract Background The level of expressed emotion (LEE) is a four-factor questionnaire that measures expressed emotion (EE) as perceived by the recipient. These factors are: perceived lack of emotional support, perceived intrusiveness, perceived irritation, and perceive criticism. The four factors of the LEE has previously been found to be related to psychological disorders and has good psychometric properties for adults. However, it has not previously been studied in adolescent populations. Methods A total of 311 adolescents participated in this study. Using structural equation modeling, confirmatory factor analyses were conducted to examine if the LEE also had the same four-factor structure for adolescents as it does for adults. Results The confirmatory factor analyses demonstrated that the LEE's fourfactor structure also applied to adolescents. The internal consistency of the scales were good and all the inter-correlations between the scales were significant. Additionally, the factors were significantly correlated to adolescent depressive and anxiety symptom score dimensions. Conclusion These findings seem to indicate that the LEE may be a good instrument in the measurement of adolescents perceived EE.

Key words adolescent - anxiety - criticism depression - expressed emotion

Dr. W.W. Hale III $(\bowtie) \cdot$ Q.A.W. Raaijmakers $\cdot$ W. Meeus

Research Center Adolescent Development

Utrecht University

P.O. Box 80.140

3508 TC Utrecht, The Netherlands

Tel.: +31-30/253-4601

E-Mail: b.hale@fss.uu.nl

C. Gerlsma

Dept. of Clinical Psychology

University of Groningen

Groningen, The Netherlands

\section{Introduction}

In earlier studies it has been demonstrated that there is a strong relationship between high parental expressed emotion (EE) interviews (i.e., Camberwell Family Interview: CFI [1]) and child and adolescent psychopathology development [2-5]. Additionally, it has been shown that low parental EE in these interviews is related to depression remission in adolescents [6].

The CFI is conducted by interviewing an important person in the life of the patient, such as the patient's parent or spouse, and from this interview the emotions this person expresses about the patient are measured. In addition to interviews, questionnaire studies of the perception of EE of adult patients to their 'important other' (i.e., parent or partner) have found a strong relationship between perceived $\mathrm{EE}$ and adult psychopathology [7-9].

Hence, it is clear that there is a strong relationship between parental expressed emotion and child and adolescent psychopathology, as measured by CFI interview, and between adult perceived expressed emotion and adult psychopathology, as measured by questionnaire. However, no attention has yet been given to the relationship between adolescent perceived $\mathrm{EE}$ and adolescent psychopathology. This is curious since EE theory assumes that the way parents talk about their child indicates how they interact with their child [10] and it has been found that negative parent-adolescent interactions have been shown to be strongly related to adolescent symptoms of depression [11] and anxiety [12]. Additionally, it has noted that negative adolescent-parent interactions are strongly related to the adolescent's perception of the interaction [13].

It should be noted that much EE research has focused on the CFI interview which has been shown to be an reliable predictor of relapse in many different psychopathologies, such as depression, anxiety, and schizophrenia $[9,14]$. However, in a review of the EE literature, Kavanagh [9] noted that the status of the 
EE concept should not rest on a single operationalization.

A different operationalization of $\mathrm{EE}$ is to measure what the receiver of the EE experiences, in other words, the person's perception of the EE. One instrument that measures perceived $\mathrm{EE}$ is the LEE questionnaire [LEE: 15, 16, 17]. While the LEE questionnaire, originally developed by Cole and Kazarian [15], has undergone revisions, the present day LEE is a 38-item questionnaire consisting of four factors: perceived lack of emotional support, perceived intrusiveness, perceived irritation and perceived criticism. The total score of the four factors is entitled perceived EE. These factors are reflective of EE theory and research $[16,17]$. In the study by Gerlsma and Hale [16] it was found that all four factors of the LEE predicted improvement in clinically depressed adult patients. However, the LEE has not previously been studied in an adolescent population.

Due to the aforementioned, the purpose of this present study is two-fold. First, this study examines if the LEE also has a four-factor structure for adolescents. Additionally, the internal consistency and scale inter-correlations of the resulting LEE scales are examined. Secondly, it is explored if the adolescent perceptions of parental EE (i.e., LEE scales) are related to adolescent psychopathological symptom dimensions, as has been found in CFI interview studies of parental EE and adolescent psychopathology.

\section{Methods}

\section{Participants}

In 2002, 321 junior high students participated in this study. These students came from 12 different Dutch junior high schools in the Utrecht province of The Netherlands. The data collected for this study is a sub-sample of a larger, ongoing research study of Dutch adolescent students and their families. Of the initial 321 students, $10(3 \%)$ students turned in blank LEE questionnaires, hence were excluded from further analyses. The excluded student group did not significantly differ from the researched group (311 students) in terms of age, gender or family composition.

The adolescent population was comprised of 154 (49.5\%) boys and $157(50.5 \%)$ girls. The age of the adolescents ranged from 11 to $15(M=13.2 ; \mathrm{SD}=0.52)$; the large majority of the adolescents were 13 years of age $(70.1 \%)$. Of the 311 adolescents, $305(98 \%)$ came from two parent families. The remaining $2 \%$ were divided over families with a single mother $(n=2)$, a single father $(n=1)$, a mother and stepfather $(n=2)$, and a father and stepmother $(n=1)$.

\section{Procedure}

The adolescents that participated in this study filled in three questionnaires, which takes approximately $35 \mathrm{~min}$, at home, under the supervision of a research assistant.

Before the study, both adolescents and their parents received written information. If the adolescent elected to participate, the parents were then required to provide written informed consent; less than $1 \%$ elected not to participate. The research assistant then called the home phone number of the adolescent (which was requested on the consent form) and made an appointment with the adolescent when the assistant could come to their home to present the questionnaires. Verbal instructions were given just prior to the testing to compliment the written instructions printed above each questionnaire. Other research assistants conducted the data entry to ensure that the data remained anonymous.

\section{Measures}

This study employed the LEE which consists of four factors: perceived lack of emotional support (pLES: 19 items), perceived intrusiveness (pIN: seven items), perceived irritation (pIR: seven items), and perceived criticism (pC: five items) [16]. Each item is scored on a scale from 1 to 4 (1: untrue; 2: somewhat untrue; 3: somewhat true; 4 : true). The total score of the 38 items is entitled perceived expressed emotion ( $\mathrm{pEE}$ ).

In addition to the LEE, the adolescents also filled in the children's depression inventory (CDI [18]) and the screen for child anxiety related emotional disorders (SCARED $[19,20]$ ) questionnaires.

The CDI is a 27-item questionnaire designed to assess child and adolescent depressive symptom dimensions. Each item is scored on a scale from 1 to 3 (1: untrue; 2: somewhat true; 3: true). It consists of one scale, a score total of the 27 items. The internal consistency of the CDI was good (Cronbach's alpha $=0.89$ ).

The SCARED is a 38 -item questionnaire that measures child and adolescent anxiety symptom dimensions. The SCARED items are scored on a scale from 1 to 3 (1: almost never; 2: sometimes; 3: often). The total of the 38 item scores assesses general anxiety disorder symptoms (SCARED total score). The internal consistency of the SCARED was good (Cronbach's alpha $=0.92$ ).

To obtain the largest possible number of complete cases entering in subsequent analyses, missing item values for all three questionnaires were first substituted by their relative mean [21]. Remaining missing scale scores were estimated within the structural equation modeling computer program (AMOS [22]).

\section{Strategy of analyses}

In order to examine the psychometric properties of the LEE, several analyses were conducted. To test the factor structure of the LEE, both a one-factor model and the theoretic four-factor model of the LEE were tested in confirmatory factor analyses (CFA).

For these analyses, the structural equation modeling program AMOS was used [22] employing the Maximum Likelihood estimation method. The model fits were evaluated by means of three indices: the relative discrepancy index (CMIN/DF; a value of 3 or lower represents a good fit), the Tucker-Lewis index (TLI; a comparative index that corrects for both sample size and model complexity with a value of 0.90 indicative of a good fit), the root mean square error of approximation (RMSEA, which estimates the likelihood of model misspecification with a value of 0.05 or less indicative of a good fit). Moreover, two further indices were examined specifically designed for the comparison of models: the expected cross-validation index (ECVI, which assesses the likelihood of model cross-validation with similar sized samples from the same population) and the akaike information criterion (AIC reflecting the extent to which estimates will cross-validate in future samples). In the comparison of different models, smaller values of ECVI and AIC represent a better fit.

After determining which model best represented the data, the adolescent population was divided into a gender group (boys and girls) and an age group (younger: 11-13 years of age, 73.7\%; older: 14-15 years of age, $26.3 \%$ ) in order to test in multi-group confirmatory factor analyses whether there existed differences between these groups in the factor structure of the LEE. Since the LEE has not been studied before in an adolescent population, these analyses were conducted since gender and age differences could be of potential interest. Additionally, the reliabilities of the LEE scale scores, the adolescents' mean scores for the scales and the scales inter-correlations were calculated.

Following the confirmatory factor analyses the LEE scores were correlated to the depression and anxiety symptom dimension scores to explore their relationship with the psychopathology 
Table 1 Fit statistics for baseline and final models of the one factor and four factors solution for the LEE

\begin{tabular}{|c|c|c|c|c|c|c|c|}
\hline & $\chi^{2}$ & $d f$ & $\chi^{2} / d f$ & TLI & RMSEA & AIC & ECVI \\
\hline \multicolumn{8}{|c|}{ One factor solution } \\
\hline Baseline & 1891.8 & 665 & 2.85 & 0.683 & 0.077 & 211.9 & 6.838 \\
\hline Final & 1678.3 & 663 & 2.53 & 0.737 & 0.070 & 1910.4 & 6.162 \\
\hline \multicolumn{8}{|c|}{ Four factor solution } \\
\hline Baseline & 1231.6 & 659 & 1.87 & 0.851 & 0.053 & 1471.6 & 4.747 \\
\hline Final & 1034.8 & 657 & 1.58 & 0.901 & 0.043 & 1278.8 & 4.125 \\
\hline Girls & 938.9 & 657 & 1.43 & 0.870 & 0.052 & & \\
\hline Boys & 936.4 & 657 & 1.43 & 0.861 & 0.053 & & \\
\hline Young & 964.5 & 657 & 1.47 & 0.892 & 0.045 & & \\
\hline Old & 888.3 & 657 & 1.35 & 0.808 & 0.066 & & \\
\hline
\end{tabular}

TLI: Tucker-Lewis index; RMSEA: Root mean square error of approximation; AIC: Akaike information criterion; ECVI: Expected cross-validation index symptom dimensions. Possible age and gender score differences were evaluated by multivariate analysis of variance tests (MANOVA with Bonferroni type adjustment).

\section{Results}

\section{Confirmatory factor analysis}

We first tested a baseline model in which none of the residual error terms were allowed to be correlated. Next, a final model was tested, in which two pairs of residuals were allowed to correlate justified by the considerable overlap in content of these paired items (i.e., two items of the emotional support subscale sharing the keyword "accuse" and two items of the irritability subscale sharing the keyword "stress"). Both the baseline and the final models were tested in a one factor and a four-factor solution. The resulting model fit statistics are reported in Table 1.

The four-factor model clearly showed a better fit than the one-factor model $\left(\Delta \chi^{2}(6)=643.5\right)$. The standardized regression weights of the LEE four-factor model, the corresponding LEE questions and the correlations between the factors are presented in Table 2 .

Since the four-factor model had a significantly better fit and can be related to the theoretical assumptions of the LEE, this model was further investigated for possible gender and age score differences. First, the four-factors structure was examined within each subsample differing in age and gender, separately. The resulting fit statistics are reported in Table 1, and suggest a reasonable fit for each subsample. Next, multi-group confirmatory factor analysis showed no difference in fit of the fourfactor model for the groups differing in age $\left(\Delta \chi^{2}\right.$ $(6)=5.49, p=0.48)$ or gender $\left(\Delta \chi^{2}(6)=8.49\right.$, $p=0.20)$, demonstrating that the four-factor model had an equally good fit for both younger and older adolescents and the boy and girl adolescents.

\section{Internal consistency, mean scale scores and scale score inter-correlations}

Additionally, it was found that the internal consistency of the LEE scales was satisfactory to good.
Cronbach's alphas for the individual scales were: pLES $=0.88$ (in subsamples ranging from 0.87 to $0.89), \mathrm{pIN}=0.83($ range $0.78-0.85), \mathrm{pIR}=0.82$ (range $0.81-0.83$ ) and $\mathrm{pC}=0.73$ (range 0.70-0.77). Cronbach's alpha for the total score, pEE, was 0.93 (with the same value for all of the subsamples).

The adolescents' mean scores for the scales were: pLES $=1.47 \quad(\mathrm{SD}=0.37), \quad \mathrm{pIN}=2.22 \quad(\mathrm{SD}=0.60)$, $\mathrm{pIR}=1.62(\mathrm{SD}=0.51), \mathrm{pC}=1.58(\mathrm{SD}=0.49)$ and $\mathrm{pEE}=1.65(\mathrm{SD}=0.37)$. The data for the adolescents' mean scores for the scales were slightly negatively skewed with skewed values of the scales ranging from -0.471 to -1.243 . However, as noted by Klein [23], maximum likelihood estimates are relatively unaffected by slightly skewed data. Finally, it was noted that all the LEE scale scores were significantly correlated to one another. These inter-correlations are presented in Table 3.

\section{Analyses of the adolescent LEE scores to the adolescent depression and anxiety symptom dimension scores}

All the LEE scales correlated significantly to the depression and anxiety symptom dimension scores. These correlations are presented in Table 4.

For the multivariate analysis of variance (MANOVA) attention was first given to the main effects that gender and age had on the adolescent LEE scale scores. It was found that neither group had a significant main effect (Gender: $F(4,311)=1.53, p=0.19$; Age: $F(4,311)=0.63, p=0.86)$. Therefore, no further analyses were given to the individual LEE scales in respect to gender or age.

\section{Discussion}

In this study it was demonstrated that the LEE, a questionnaire designed to measure perceived $\mathrm{EE}$, possess a four-factor structure for adolescents, as has been previous demonstrated for adults [e.g., 16]. The internal consistency of the scales were good and all the inter-correlations between the scales were significant. Additionally, it was found that the adolescent 
Table 2 Standardized regression weights of the LEE four-factor model after confirmatory factor analysis and the corresponding LEE questions

\begin{tabular}{|c|c|c|c|c|}
\hline \multicolumn{2}{|l|}{ LEE Item } & \multicolumn{3}{|c|}{$\begin{array}{l}\text { Standardized } \\
\text { regression weight }\end{array}$} \\
\hline My parents... & $\mathrm{pLES}^{\mathrm{a}}$ & $\mathrm{plR}$ & $\mathrm{pIN}$ & $\mathrm{pC}$ \\
\hline Try to reassure me when I'm not feeling well ${ }^{\mathrm{b}}$ & 0.698 & & & \\
\hline Are sympathetic towards me when I'm ill or upset ${ }^{b}$ & 0.692 & & & \\
\hline Are considerate when I'm ill ${ }^{\mathrm{b}}$ & 0.675 & & & \\
\hline Can see my point of view ${ }^{b}$ & 0.649 & & & \\
\hline Often accuses me of making things up when I'm not feeling well & 0.621 & & & \\
\hline Are understanding if I make a mistake ${ }^{\mathrm{b}}$ & 0.632 & & & \\
\hline Make me feel relaxed when they are around ${ }^{b}$ & 0.636 & & & \\
\hline Understand my limitations ${ }^{\mathrm{b}}$ & 0.622 & & & \\
\hline Try to make me feel better when I'm ill ${ }^{b}$ & 0.565 & & & \\
\hline Hear me out ${ }^{b}$ & 0.560 & & & \\
\hline Are tolerant with me, even when I'm not meeting their expectations ${ }^{b}$ & 0.545 & & & \\
\hline Make me feel valuable as a person ${ }^{\mathrm{b}}$ & 0.537 & & & \\
\hline Accuse me of exaggerating when I say I'm unwell & 0.498 & & & \\
\hline Calm me down when I'm upset ${ }^{b}$ & 0.515 & & & \\
\hline Will not help me when I'm upset & 0.454 & & & \\
\hline $\begin{array}{l}\text { Are willing to gain more information to understand } \\
\text { my condition, when I'm not feeling well }\end{array}$ & 0.453 & & & \\
\hline Will take it easy with me, even if things aren't going right ${ }^{b}$ & 0.413 & & & \\
\hline Don't know how to handle my feelings when I'm unwell & 0.384 & & & \\
\hline Expect the same level of effort from me, even if I don't feel well & 0.365 & & & \\
\hline Fly off the handle when I don't do something well & & 0.759 & & \\
\hline Get irritated when things don't go right & & 0.686 & & \\
\hline Make matters worse when things aren't going well & & 0.618 & & \\
\hline Get upset when I don't check in with them & & 0.611 & & \\
\hline Can cope well with stress ${ }^{\mathrm{b}}$ & & 0.537 & & \\
\hline Can't think straight when things go wrong & & 0.577 & & \\
\hline Are able to be in control in stressful situations & & 0.484 & & \\
\hline Are always nosing into my business & & & 0.861 & \\
\hline Have to know everything about me & & & 0.781 & \\
\hline Are always interfering & & & 0.737 & \\
\hline Butt into my private matters & & & 0.721 & \\
\hline Often check up on me to see what I'm doing & & & 0.587 & \\
\hline Insist on knowing where I'm going & & & 0.456 & \\
\hline Don't pry into my life $\mathrm{e}^{\mathrm{b}}$ & & & 0.400 & \\
\hline Are critical of me & & & & 0.709 \\
\hline Get annoyed when I want something from them & & & & 0.702 \\
\hline Show me that they love me $\mathrm{b}^{\mathrm{b}}$ & & & & 0.623 \\
\hline Try to change me & & & & 0.572 \\
\hline Usually agree with $\mathrm{me}^{\mathrm{b}}$ & & & & 0.434 \\
\hline
\end{tabular}

perceived EE (LEE) scores correlated significantly to their self rated depression and anxiety symptom dimension scores.

In the CFA it was demonstrated that the LEE fourfactor model had a significantly better fit than the one-factor model. Hence the findings of this study demonstrate that the LEE also possesses the same theoretic four-factor structure for adolescents as it does for adults. Moreover it was also demonstrated that the four-factor model had an equally good fit for both younger and older adolescents and the boy and girl adolescents.

It was further noted that the adolescents' LEE questionnaire scores were not different for either the age or the gender groups. Since the LEE has not previously been studied in adolescent populations, the only comparisons that can drawn are from adult populations. In LEE studies of adults, Gerlsma [17] and Startup [24] found no difference for age, however Gerlsma did find that female adults scored slightly higher than male adults whereas Startup did not. So while it appears that the perception of EE as measured by the LEE is unrelated to age for adults and adolescents, no definite conclusion can be drawn as to gender.

As was noted in the introduction, previous studies of adolescent psychopathology and the CFI's EE interviews have found positive correlations between the two. Although the correlations in Table 4 are modest, the adolescent LEE scores were significantly related to all the adolescent self-rated depression and anxiety symptom dimensions. One possible explanation for the modest correlation results is that the adolescents in this study came from the general 
Table 3 Inter-correlations of the LEE scale scores

\begin{tabular}{|c|c|c|c|c|}
\hline $\mathrm{pLES}^{\mathrm{a}}$ & pIR & pIN & $\mathrm{pC}$ & $\mathrm{pEE}$ \\
\hline pLES & $0.70^{* *}$ & $0.40^{* *}$ & $0.70^{* *}$ & $0.91^{* *}$ \\
\hline pIR & & $0.43^{* *}$ & $0.69^{* *}$ & $0.84^{* *}$ \\
\hline pIN & & & $0.48^{* *}$ & $0.68^{* *}$ \\
\hline pC & & & & $0.83^{* *}$ \\
\hline
\end{tabular}

${ }^{* *} p<0.001$

${ }^{a}$ Perceived lack of emotional support (pLES), Perceived irritability (pIR), Perceived intrusiveness (pIN), Perceived criticism (pC), Perceived expressed emotion $(\mathrm{pEE})$

Table 4 Correlations of the adolescent LEE scores to the adolescent depression and anxiety symptom dimension scores

\begin{tabular}{llllll}
\hline & $\mathrm{pLES}$ & $\mathrm{plR}$ & $\mathrm{pIN}$ & $\mathrm{pC}$ & $\mathrm{pEE}$ \\
\hline Depression & $0.33^{* *}$ & $0.16^{* *}$ & $0.30^{* *}$ & $0.32^{* *}$ & $0.34^{* *}$ \\
Anxiety & $0.18^{*}$ & $0.17^{*}$ & $0.26^{* *}$ & $0.23^{* *}$ & $0.24^{* *}$ \\
\hline
\end{tabular}

$* p<0.01$

${ }^{* *} p<0.001$

${ }^{a}$ Perceived lack of emotional support (pLES), Perceived irritability (pIR), Perceived intrusiveness (pIN), Perceived criticism (pC), Perceived expressed emotion (pEE)

population as opposed to coming from psychiatric patient groups.

Perceived EE have been related to adult psychiatric disorders $[1,16,25,26]$. However, the perception of $\mathrm{EE}$ on the part of the adolescent has not in the past been studied, despite the knowledge that high EE has an effect on the mental wellbeing of adolescents. While it is important to reiterate that this is an adolescent sample from the general population who selfrated depression and anxiety symptom dimensions, hence cannot be equated to actual psychiatric disorders, these findings are still interesting. Since these findings of adolescent self-rated emotional states are in agreement with previous findings of high EE environments and adolescent psychopathology, it might be that adolescent perceived EE and psychopathology may be as relevant a line for future investigation has it has been for adult psychopathology.

\section{Limitations and future research}

Several potential limitation of this study should be mentioned. The first our use of only adolescent self reports. Since this study only used the adolescent self reports of EE, as opposed to parental interviews, it is possible that the correlations of the LEE and depression and anxiety measures are artificially inflated. While many studies have assumed that parents are better reporters of their own upbringing behaviors than adolescents are, Dekovic et al. [27] has noted two compelling reasons why adolescent reports may in fact be a better representation. First, parents have been found in research to have a strong positive bias of their own upbringing behaviors and parental reports have been shown to have less agreement with outside observers than adolescent reports have [28]. Secondly, the subjective experience of being "brought up" has more influence on adolescent development [29] and is more strongly related to adolescent adjustment and mental health than parents reports of their upbringing behaviors [30, 31]. Dekovic et al. [27] quotes Gesac and Schwalbe [30] "It is our perception of others' attitude or behavior which are more consequential for our own attitudes and behavior than the actual attitudes or behavior of others" ( $p$ 42). Therefore, in light of our findings, we would suggest that our use of adolescent reports of perceived parental EE is justified.

Additionally, self report questionnaires are naturally different than direct behavioral observations. As has been demonstrated in pervious studies, direct measures of family member interactions have been related to psychopathological disorders. This has been done by video-taped interactions [e.g., 32]. However, the advantage of questionnaires is they are easily conducted, allow for repeated measures, require no training or lengthy interpretation and allow for the target person's own perception to be measured. While not a substitute of direct interaction measures, they can be a helpful addition to the tools of both researchers and clinicians.

It should also be noted that this is a cross-sectional study, hence any inferences to the causal role that perceived EE may have on adolescent mood or anxiety symptom dimensions should not be drawn. Their relationship may, in fact, be bi-directional in nature such as has been found in other studies of negative interactions (e.g., EE) and mood [33]. Future longitudinal studies would be required to examine how each of these factors affects the other and explore if perceived EE questionnaire data has the same predictive properties of CFI interview EE data.

Lastly, while mood and anxiety symptom dimensions were measured by questionnaires, it should be again stated that such measures are not equivalent to psychiatric disorders. Additionally, this study examined adolescents from the general population. Therefore, while these findings may reflect how adolescent perceived EE is related to emotional states, future study of perceived EE is needed to relate this to depressive and anxiety disorders.

\section{Conclusion}

In summary, this study it was found that the theoretic four-factor structure of the LEE questionnaire applies to adolescents, as has been previously been demonstrated in adult populations, and that the LEE scales are related to adolescent depressive and anxiety symptom dimensions. Additionally, it was demonstrated that the four-factor model had an equally good fit for both younger and older adolescents and the boy and girl adolescents. The internal consistency of the 
factors were good and all the inter-correlations between the factors were significant. These findings are encouraging and seem to indicate that the LEE may be a welcome addition to the instrument arsenal in the measurement of perceived EE and adolescents.

Acknowledgements This study was funded by the Research Center Adolescent Development at Utrecht University.

\section{References}

1. Yan LJ, Hammen C, Cohen AN, Daley SE, Henry RM (2004) Expressed emotion versus relationship quality variables in the prediction of recurrence in bipolar patients. J Affect Disord 83:199-206

2. Asarnow JR, Goldstein MJ, Tompson M, Guthrie D (1993) One year outcomes of depressive disorders in child psychiatric inpatients: evaluation of the prognostic power of a brief measure of expressed emotion. J Child Psychol Psychiatry 34:129-137

3. Schmidt U, Humfress H, Treasure J (1997) The role of general family environment and sexual and physical abuse in the origins of eating disorders. Eur Eat Dis Rev 5:184-207

4. Van Noppen B, Steketee G (2003) Family responses and multifamily behavioral treatment for obsessive-compulsive disorder. Brief Treat Crisis Intervention 3:231-247

5. Vostanis P, Nicholls J, Harrington R (1994) Maternal expressed emotion in conduct and emotional disorders of childhood. J Child Psychol Psychiatry 35:365-376

6. McCleary L, Sanford M (2002) Parental expressed emotion in depressed adolescents: prediction of clinical course and relationship to comorbid disorders and social functioning. J Child Psychol Psychiatry 43:587-595

7. Chambless DL, Steketee G (1999) Expressed emotion and behavior therapy outcome: a prospective study with obsessivecompulsive and agoraphobic outpatients. J Con Clin Psychol 67:658-665

8. Hooley JM, Teasdale JD (1989) Predictors of relapse in unipolar depressives: expressed emotion, marital distress, and perceived criticism. J Ab Psychol 98:229-235

9. Kavanagh DJ (1992) Recent developments in expressed emotion and schizophrenia. Brit J Psychiatry 160:601-620

10. McCarty CA, Lau AS, Valeri SM, Weisz JR (2004) Parent-child interactions in relation to critical and emotionally overinvolved expressed emotion (EE): is EE a proxy for behavior? J Ab Child Psychol 32:83-93

11. Herman-Stahl M, Petersen AC (1999) Depressive symptoms during adolescence: direct and stress-buffering effects of coping, control beliefs, and family relationships. J Appl Dev Psychol 20:45-62

12. Woodruff-Borden J, Morrow C, Bourland S, Cambron S (2002) The behavior of anxious parents: examining mechanisms of transmission of anxiety from parent to child. J Clin Child Adol Psychol 31:364-374

13. Hudson JL, Rapee RM (2004) From anxious temperament to disorder: an etiological model. In: Turk CL (ed) Generalized anxiety disorder: advances in research and practice. Guilford Press, New York

14. Butzlaff RL, Hooley JM (1998) Expressed emotion and psychiatric relapse. Arch Gen Psychiatry 55:547-552
15. Cole JD, Kazarian SS (1988) The level of expressed emotion scale: a new measure of expressed emotion. J Clin Psychol 44:392-397

16. Gerlsma C, Hale III WW (1997) Predictive power and construct validity of the level of expressed emotion (LEE) scale: depressed out-patients and couples from the general community. Brit J Psychiatry 170:520-525

17. Gerlsma C, van der Lubbe PM, van Nieuwenhuizen C (1992) Factor analysis of the level of expressed emotion scale, a questionnaire intended to measure "perceived expressed emotion". Brit J Psychiatry 160:385-389

18. Kovacs M (1981) Rating scales to assess depression in schoolaged children. Acta Paedopsychiatrica 46:305-315

19. Birmaher B, Khetarpal S, Brent D, Cully M, Balach L, Kaufman J, Neer S (1997) The screen for child anxiety related emotional disorders (SCARED): scale construction and psychometric characteristics. J Am Acad Child Adol Psychiatry 36:545-553

20. Hale III WW, Raaijmakers Q, Muris P, Meeus W (2005) Psychometric properties of the screen for child anxiety related emotional disorders (SCARED) in the general adolescent population. J Am Acad Child Adol Psychiatry 44:283-290

21. Raaijmakers QAW (1999) Effectiveness of different missing data treatments in surveys with Likert-type data: introducing the relative mean substitution approach. Ed Psychol Measure 59:725-748

22. Arbuckle JL, Wothke W (1999) Amos 4.0 user's guide. SmallWaters, Chicago

23. Klein RB (2004) Principles and practice of structural equation modeling. Guilford Press, New York

24. Startup M (1999) Confirmatory factor analysis of the level of expressed emotion (LEE) scale. Brit J Med Psychol 72:421424

25. Forster J, Finlayson S, Bentall R, Day J, Randall F, Wood P, Reid D, Rogers A, Healy D (2003) The perceived expressed emotion in staff scales. J Psychiat Mental Health Nursing 10:109-117

26. Renshaw KD, Chambless DL, Steketee G (2003) Perceived criticism predicts severity of anxiety symptoms after behavioral treatment in patients with obsessive-compulsive disorder and panic disorder with agoraphobia. J Clin Psychol 59:411-421

27. Dekovic M, ten Have M, Vollebergh WAM, Pels T, Osterwegel A, Wissink IB, De Winter AF, Verhulst FC, Ormel J (2005) The cross-cultural equivalence of parental rearing measure: EMBUC. European J Psychol Assess 22:85-91

28. Cook WL, Goldstein MJ (1993) Multiple perspective on family relationships: a latent variables model. Child Develop 64:13771388

29. Steinberg L, Lamborn SD, Dornbusch SM, Darling N (1992) Impact of parenting practices on adolescent achievement: authoritative parenting, school involvement, and encouragement to succeed. Child Dev 63:1266-1281

30. Gesac V, Schwalbe ML (1986) Parental behavior and adolescent self-esteem. J Marriage Fam 48:37-46

31. Noller P (1995) Parent-adolescent relationship In: Fitspatri MA, Vangelisti AL (eds) Explaining family interactions. Sage Publications, Thousand Oaks,CA

32. Hale III WW (2001) Behavioral social support between remitted depressed patients with partners and strangers. J Affect Disord 64:285-289

33. Coyne JC, Burchill SAL, Stilles WB (1991) An interactional perspective on depression. In: Snyder CR, Forsyth DO (eds) Handbook of social and clinical psychology. Pergamon, New York 